\title{
La fe que cura ${ }^{1}$
}

Introducción: Jean-Martin Charcot, del localizacionismo a la psicología

Apenas es necesaria una presentación para un autor como Charcot que enseguida se convirtió en un clásico, sus obras fueron traducidas a todas las lenguas y la amplitud de sus investigaciones es asombrosa: el reumatismo crónico, la gota, las hemorragias cerebrales, la ataxia, la esclerosis lateral amiotrófica, la afasia, las localizaciones cerebrales...; mantuvo una clientela privada internacional muy famosa entre la que se encontraban ministros, banqueros, grandes duques...; creó la prestigiosa escuela de la Salpêtrière formando a innumerables discípulos; fundó incluso una rama nueva de la medicina, la neurología; son conocidos sus cursos magistrales de los viernes y sus lecciones de los martes; famoso por sus veladas a las que asistía la flor y nata de la sociedad de la época, médicos, políticos, pintores, escultores, arquitectos, literatos... Pero quizás hoy sea más recordado por haber elevado la histeria a la dignidad de enfermedad.

El año 1870 marcó un cambio de orientación en la vida de Charcot. Por aquel entonces en el hospital de la Salpêtrière existía la sección de Delasiauve donde se encontraban hospitalizados los alienados, los histéricos y los epilépticos, todos mezclados; el mal estado del edificio obligó a la administración del hospital a iniciar su remodelación, lo que hizo que los enfermos hubiesen de ser evacuados. Esa mezcolanza de diferentes enfermos no congeniaba con la idea que en la época se tenía de una investigación seria y rigurosa, por lo que se creó una sección específica para histéricos y epilépticos que se confió a Charcot, quien desde entonces se consagró al estudio de la histeria, aislándola, definiéndola y "descubriendo" la existencia de la histeria masculina.

Para entonces ya se había labrado su fama en el campo de la anatomía patológica habiendo desarrollado su método anatomoclínico aplicado a las enfermedades nerviosas, y utilizó el mismo método en el estudio de la histeria. Consideraba la histeria y la epilepsia como las dos grandes neurosis que compartían el síntoma de la convulsión; a partir de ahí empezó su trabajo nosológico. Para ello utilizó a los que llamaba su "museo vivo", los más de cinco mil enfermos que eran la población estable de su Sección, verdadera 'citta dolorosa', haciendo así suyo el postulado de Bernard $^{2}$, quien decía que para aprender algo sobre la vida de hombres y animales hay que haber visto morir a muchos. Charcot se hacía traer a un enfermo a su gabinete, le miraba, le pedía que hablase o que hiciese un movimiento, después hacía venir a otro y hacía lo mismo, y a otro, y los comparaba. Esta observación detallada, visual, es el fundamento de sus descubrimientos, método en el que no hay que menospreciar las grandes dotes artísticas que poseía. A veces llegaba a ver hasta a setenta u ochenta enfermos y así lograba describir el "tipo" de la enfermedad, sus características específicas, pudiendo así

'Introducción y traducción de Angel Cagigas*

${ }^{2}$ Bernard, C. Introduction d l'étude de la médicine expérimentale. Baillière, París, 1865, p. 173.

Rev. Asoc. Esp. Neuropsiq., 2001, vol XXI, n. ${ }^{\circ} 77$, pp. 99-111 
delimitar las patologías. Janet ${ }^{3}$ definía el tipo como un conjunto de síntomas que dependen unos de otros, jerarquizados y que pueden clasificarse en grupos que se distinguen claramente de los de otras enfermedades similares. Por este camino Charcot llegó a desmentir la célebre frase de Briquet $^{4}$, según la cual la histeria era un Proteo que puede presentar mil formas sin tener ninguna, pues pudo establecer las características del ataque histérico, que podía ir precedido y acompañado de alucinaciones, desórdenes de la sensibilidad u otras perturbaciones orgánicas, y que dividió en cuatro fases: epileptoide, clównica, de actitudes pasionales o poses plásticas y delirante. Imbuido de su método anatomoclínico buscó la localización de la lesión cerebral desencadenante de la histeria sin llegar a encontrarla jamás. No por eso dejó de lado la explicación fisiológica de la histeria definiéndola como una neurosis funcional del sistema nervioso debida a una degeneración nerviosa de origen hereditario desencadenada por la acción de diversos agentes como intoxicaciones o infecciones.

A partir de entonces trabajó desde esta perspectiva que a la postre no haría sino dinamitar todo el edificio que tantos años había tardado en construir. Al no encontrar un substrato neurológico para la explicación de la histeria se lanzó al estudio de sus factores desencadenantes, y así la causa se transfiguró en una serie de agentes provocadores que acabó siendo casi interminable: el primero de todos era la herencia, pero además estaban los traumas nerviosos, los traumas morales, las intoxicaciones, los accidentes, las prácticas religiosas exageradas, el agotamiento, las epi- demias, los miedos, la diabetes, el onanismo, la escarlatina, los excesos y la continencia venéreos, el tabaco, determinadas profesiones...; y no olvidemos a este respecto la famosa anécdota según la cual en un aparte Charcot le dijo a Brouardel que en la histeria se trata siempre de lo genital, y repetía, siempre, siempre, siempre...

Poco tiempo antes Charcot se había interesado por el fenómeno de la hipnosis que acabó convirtiéndose en un fecundo campo de investigación; en un principio no pensó que la hipnosis tuviera ningún efecto terapéutico pero sí le procuraba una explicación del síntoma principal de la histeria, la mimesis, pues le permitía reproducir artificialmente diferentes síntomas histéricos poniendo de relieve lo que llamaba las leyes de la histeria. No estudió la hipnosis como fenómeno en sí mismo sino como protocolo experimental que le permitía provocar experimentalmente los síntomas histéricos, era una especie de histeria en miniatura. Estos trabajos le valieron numerosas críticas, como la de dedicarse a cultivar la histeria sin curarla o la de haberse dejado embaucar tanto por sus enfermos como por algunos de sus ayudantes, todos ellos dispuestos a satisfacer al maestro poniendo en escena lo que éste deseaba ver, o la de quienes decían que la histeria sólo existía en Francia, a lo que él replicaba sarcásticamente que incluso se podría decir que sólo existía en la Salpêtrière, como si él mismo la hubiese creado con la fuerza de su voluntad. A despecho de todas estas críticas no debe olvidarse la continua referencia de Charcot a los hechos en detrimento de la teoría, tal como ponía de relieve cuando afirmaba que la teoría es buena pero que no impide que 
HISTORIA

las cosas existan. La hipnosis se convirtió de esta forma en un modelo de la histeria y Charcot pensaba que ambos fenómenos, hipnosis e histeria, sólo podían darse en personas con un sistema nervioso débil, en degenerados.

Por mucho que se esforzó no logró dar nunca con ese substrato neurológico, esa disfunción, que suponía causa de la histeria, del 'malum sine materia'. En sus últimos días sus ideas sufrieron un vuelco hacia la psicología, con opiniones tan contrarias a su trayectoria anterior como la que le hace decir a propósito del caso de la señora Dutemple que lo que está detrás de la fuerza evocativa de la parálisis histérica que afectaba a la paciente es la idea obsesiva, el recuerdo registrado pero que no podía evocarse, y que esa fuerza evocativa podía liberarse haciendo conscientes los recuerdos, afirmando además para su satisfacción que un tratamiento exclusivamente psicológico hubiera bastado en este caso para restablecer las cosas. Es sabido que en el curso siguiente, que ya no pudo dar al encontrarle la muerte, quería abordar el estudio del estado mental de los histéricos. Un ejemplo precioso de esta nueva perspectiva lo tenemos en el texto que se ofrece a continuación, La fe que cura; al que Gilles de la Tourette ${ }^{5}$ se refería como su testamento filosófico y que dando un máximo poder a la psicogenia en la etiología de la enfermedad mental y al tratamiento exclusivamente psicológico, puede verse como una anticipación de lo que ya por entonces empezaban a fraguar alumnos como Janet, Guinon, o incluso el mismo Freud.

\section{LA FE QUE CURA}

La New Review, haciéndose eco del reciente viaje de un literato célebre a un santuario religioso y de las discusiones que ha suscitado, me pide mi opinión sobre la faithhealing ${ }^{1}$. La cuestión no es de las que me dejan indiferente. Además interesa a todo médico pues la meta esencial de la medicina es la curación de los enfermos con independencia del procedimiento curativo utilizado. En este sentido, la faith-healing me parece el ideal que debemos alcanzar pues a menudo es eficaz cuando todos los demás remedios han fracasado. Por eso desde hace tiempo en ciertos casos he intentado penetrar en la medida de lo posible en el mecanismo que la produce para utilizar así su poder, y expondré en pocas palabras la opinión que me he formado.
Añadiré que en tal materia, como en cualquier otra, jamás se ha de faltar al rigor inherente a la discusión científica; las polémicas apasionadas no sirven para nada, a no ser para enmarañarlo todo y comprometer las mejores causas. Por eso esta cuestión de la faith-healing no ha de resolverse mediante afirmaciones sin pruebas ni negaciones sin fundamentos, pues como ya he dicho pertenece enteramente al orden científico donde los únicos argumentos admisibles son los hechos estudiados y agrupados concienzudamente para así poder llegar a conclusiones.

\section{I}

Los hechos que en mi ya larga experiencia como especialista he tenido ocasión

\footnotetext{
' Gilles de la Tourette, G. "Jean Martin Charcot". En Nouvelle Iconographie de la Salpêtrière, París, 1893, p. 246.

' N. T. Se trata de la fe en la curación; el "viaje de un literato célebre a un santuario religioso" es el que Zola hizo a Lourdes (cf.

É. Zola, Les trois Villes. Lourdes. Charpentier et Fasquelle, París, 1894).
} 
HISTORIA

de observar en absoluto son hechos aislados pues la faith-healing y su resultado, el milagro - sin dar a esta palabra otra significación que la de una curación fuera de los medios ordinarios de la medicina-, responden a una categoría que no escapa al orden naturàl de las cosas. El milagro terapéutico tiene su determinismo y las leyes que presiden su génesis y su evolución empiezan a ser lo suficientemente conocidas como para que el grupo de hechos englobados bajo este vocablo se presente con un aspecto lo bastante específico como para no escapar del todo a nuestra apreciación. Por otro lado, esto es motivo de alegría pues una mayor comprensión de esas determinaciones pone cada vez más a nuestra disposición los grandes recursos de la faith-healing y así cada vez estamos menos desarmados ante la enfermedad.

Vamos a estudiar los elementos de ese determinismo. Agruparlos nos conducirá a una conclusión que sin más puedo adelantar. La curación, aparentemente extraordinaria, producto directo de la faithhealing y que en terapéutica suele denominarse milagro, en la mayoría de las ocasiones, según puede demostrarse, es un fenómeno natural que se produce en todas las épocas, en medio de las civilizaciones y las culturas más variadas, aparentemente más diferentes, y también se puede observar en la actualidad en todas las latitudes. Los hechos llamados milagrosos, y no pretendo decir nada nuevo, tienen un doble carácter: son engendrados por una disposición mental específica del enfermo; una confianza, una credulidad, una sugestionabilidad, como se dice hoy, constitutivas de la faithhealing cuyo nivel de activación varía. Por otra parte, su dominio es limitado; para pro- ducir sus efectos debe dirigirse a los casos cuya curación no exige otra intervención que este poder de la mente sobre el cuerpo, analizado de forma tan notable en el gran libro del Dr. Hack Tuke ${ }^{2}$. Ninguna intervención puede hacer que franquee sus límites pues nada podemos contra las leyes naturales. Por ejemplo, si revisamos las recopilaciones sobre las curaciones llamadas' milagrosas jamás encontraremos que la faith-healing haya hecho crecer un miembro amputado. Por el contrario, encontraremos curaciones de parálisis a cientos, pero siempre han sido de las que el profesor Russell Reynolds ${ }^{3}$ ha calificado con el término de parálisis dependent on ide $a^{4}$.

\section{II}

Sé que hoy los médicos encargados de comprobar los milagros, cuya buena fe no se pone en duda, parecen creer que la curación repentina de las parálisis o de las convulsiones no tiene nada que ver con las leyes naturales. Intentan mostrar por el contrario que los tumores y las úlceras más rebeldes son moneda corriente en el dominio de la terapéutica milagrosa. No lo niego: pienso al igual que ellos que la faith-healing en ciertos casos puede hacer desaparecer úlceras y tumores, pero creo también que a pesar de su apariencia las lesiones de ese tipo son de la misma naturaleza, de la misma esencia, que las parálisis que acabo de mencionar.

La curación más o menos repentina de las convulsiones y las parálisis se consideraba en otras épocas como un milagro terapéutico con todas las de la ley. Cuando la ciencia demostró que esos fenómenos eran de origen histérico, es decir que no eran orgánicos sino dinámicos, la curación milagrosa dejó de existir.

${ }^{2}$ Illustrations of the Influence of the Mind upon the Body in Health and Disease designed to Elucidate the Action of the Imagination. Churchill, Londres, 1872.

3 "Remarks on paralysis and other disorders of motion and sensation on idea", leído en la sección médica de la Asociación Médica Británica, Leeds, julio de 1869, en British med. Journ., noviembre de 1869.

${ }^{4} \mathrm{~N}$. T. [dependiente de una idea]. 
HISTORIA

¿Por qué digo todo esto? Si se demostrase que esos tumores y úlceras que tanto ruido hacen también son de naturaleza histérica, y que están sometidos a la misma faith-healing que las convulsiones y las parálisis, se acabaría con el milagro.

¡Por qué lanzar tales desafíos a la ciencia si al final ésta acaba por tener la última palabra!

Es mucho más simple constatar que la terapéutica milagrosa y la ciencia han sufrido una evolución paralela. No se puede hablar de una faith-healing religiosa y otra laica, se trata de la misma operación cerebral que produce idénticos efectos. $\mathrm{La}$ ciencia, cuya principal característica es que evoluciona, no pretende explicarlo todo: negaría así su propia evolución. Da su interpretación racional a medida que hace descubrimientos, ¡eso es todo! Siempre es enemiga de las negaciones sistemáticas que acaban por esfumarse a la luz de sus nuevas conquistas. Creo que su evolución no ha quedado rezagada respecto a la del milagro, y que la faith-healing siempre ha hecho desaparecer con su poder tumores y úlceras de una cierta naturaleza. En esos casos la ignorancia imperaba pues desconocíamos el secreto de ese mecanismo. Aunque ignoramos todavía muchas cosas, hoy hemos avanzado más en la vía de la interpretación científica y preveo el día, aún algo lejano, en que la realidad evidente de los hechos no encontrará ya oponentes. Estudiemos ahora los elementos del determinismo de la faith-healing.

La faith-healing se da sobre todo en los santuarios religiosos. En todas las épocas han existido taumaturgos, desde
Simón el mago hasta el príncipe de Hohenhole, a principios de este siglo, pasando por el diácono de Pâris, que han tenido el don de realizar curaciones llamadas milagrosas, es decir de inspirar la faithhealing. Estos taumaturgos que a menudo eran religiosos fundaron santuarios y sobre sus tumbas se han multiplicado los milagros que hacían en vida. Hay que poner de relieve que en los santuarios religiosos no es la propia divinidad la que intercede sino su profeta o sus discípulos. Se trata casi siempre de un simple mortal que durante su vida se ganó su beatificación haciendo milagros. Resulta curioso que algunos de estos taumaturgos sufrieran la enfermedad cuyas manifestaciones más tarde curaban: san Francisco de Asís, santa Teresa, cuyos santuarios son de los más reputados entre aquellos donde se producen milagros, eran histéricos.

La forma en que se haya creado el santuario poco importa; lo interesante desde el punto de vista del determinismo del milagro es el propio santuario. $Y$ ese determinismo se hace patente cuando se comprueba que todos los santuarios se parecen, están cortados por el mismo patrón. Siguen siendo iguales desde los tiempos más remotos de la historia hasta nuestros días, se copian unos a otros. Así pues, a través de los tiempos, entre las civilizaciones más diversas, en medio de las religiones aparentemente más dispares, las condiciones del milagro permanecen idénticas, sus leyes evolutivas son inmutables.

Estudiemos por ejemplo el Asclepión de Atenas ${ }^{5}$, hijo directo de los santuarios del antiguo Egipto pues en el Asclepión el dios curador a menudo mos-

\footnotetext{
${ }^{5}$ Cf. L'Asclépiéion d'Athènes, d'après de récentes découvertes, de Paul Girard, editado por E. Thorin, París, 1881.
} 
traba los rasgos de Serapis, el taumaturgo de los faraones. Al fondo del santuario, la estatua milagrosa; entre los servidores del templo encontramos sacerdotes-médicos encargados de comprobar o ayudar en las curaciones, esto es, el equipo médico que no falta en los santuarios actuales cuando tienen cierta importancia.

Encontramos también bajo los pórticos del Asclepión unos personajes muy singulares: los intercesores, los que en diversas ciudades se ocupan de rendirse ante el dios curador para implorar su protección en representación de sus clientes.

En todo el Poitou existen unas ancianas que tienen por oficio ir a interceder ante la tumba milagrosa de santa Radegunda por quienes aunque animados por la faith-healing no pueden o no quieren desplazarse.

Dejemos a estos intermediarios para pasar a considerar a los suplicantes que van en persona. Quienes están animados por la faith-healing se encaminan desde todos los demos de Grecia hacia el santuario para curar sus males. A su llegada depositan ricos presentes sobre el altar y se sumergen en la fuente purificadora que mana en el templo de Esculapio para ganár el favor del dios.

“ Por Zeus!, grita la mujer a la que Carión, el criado de la comedia de Aristófanes, cuenta las aventuras alegóricas de Ploutos, iqué mayor fortuna para un anciano que remojarse en el agua fría!"

Los siglos han pasado pero la fuente sagrada sigue manando.
Tras estos preliminares se permite a los suplicantes pasar la noche bajo los pórticos del templo. Comienza así la incubación, novena propiciatoria en la que la faith-healing se exalta cada vez más, por autosugestión, por contagio, por una especie de fuerza inconsciente, y entonces el milagro se produce... si procede.

Quienes se curaban en el Asclepión ornaban las paredes del templo con himnos votivos y sobre todo con brazos, piernas, cuellos, senos, de materias más o menos preciosas, objetos representativos de la parte del cuerpo curada por la intervención milagrosa. Los santuarios actuales siguèn adornados con estos exvotos grabados en mármol, y a la puerta mil comerciantes, como antaño en Atenas, venden brazos, manos, niños de cera que adornan los accesos a la tumba del santo o las paredes de la gruta. El rosario de la novena en la que se exalta la fe recuerda el del musulmán que se inclina ante el sepulcro del venerado morabito.

En todas las épocas, en todas las latitudes, entre los paganos, los cristianos o los musulmanes, la faith-healing ha revestido el mismo carácter. Los santuarios y las prácticas propiciatorias son análogos. Sólo son diferentes las estatuas del dios curador pero la mente humana, siempre la misma, las confunde en una misma evocación.

\section{III}

En general la faith-healing no desarrolla espontáneamente toda su intensidad curativa.

Un enfermo oye decir que en tal santuario se producen curaciones milagrosas: 
es muy raro que vaya allí inmediatamente. Mil obstáculos materiales impiden al menos temporalmente su desplazamiento: a un paralítico o a un ciego no les es fácil embarcarse en un largo viaje, por mucho dinero que tengan. Pregunta a sus allegados, pide información sobre las curas maravillosas de las que ha oído rumores. No oye más que palabras alentadoras de sus allegados e incluso de su médico. Éste no quiere quitarle la última esperanza a su enfermo, sobre todo si cree que la enfermedad de su cliente es susceptible de remitir mediante la faithhealing que él no ha sabido inspirarle. Además contradecirle no tendría otro efecto que exaltar la creencia en la posibilidad de una curación milagrosa. La faith-healing comienza a nacer, se desarrolla cada vez más, la incubación la prepara, el peregrinaje se convierte en una idea fija. Los desheredados de la fortuna se mortifican pidiendo limosnas que les permitan alcanzar el lugar santo; los ricos son generosos con los pobres para ganarse el favor de la divinidad: todos rezan con fervor e imploran su curación. En esas condiciones el estado mental no tarda en dominar al estado físico. El cuerpo rompe con una rutina fatigosa, los enfermos llegan al santuario con la mente sugestionada. "Como la mente de la enferma, dijo Barwell' ${ }^{6}$, está dominada por la firme convicción de que debe curarse, ella se curará indefectiblemente". Un último esfuerzo: una ablución en la piscina, una última oración más ferviente ayudada por el culto exterior, y la faith-healing produce el efecto deseado: la curación milagrosa se hace realidad.

\section{IV}

¿Cuáles son los efectos directos de la faithhealing? ¿Cuáles son las enfermedades en

\footnotetext{
${ }^{6}$ The Lancet, 28 de noviembre de 1858.
}

las que produce efectos curativos incontestables? Para responder a estas preguntas estudiemos los documentos encontrados en los santuarios.

Hace un momento he hablado de los exvotos simbólicos que los enfermos curados colgaban de las murallas del Asclepión y que hoy seguimos encontrando en los santuarios más venerados. Esos brazos, esas piernas de mármol o de cera son representaciones imperfectas de la realidad, pues aunque un brazo puede sufrir veinte enfermedades diferentes siempre se representa de la misma manera, la misma forma tradicional que se descubre en las excavaciones o que se contempla en los santuarios actuales. ¡La figuración directa, real, de la enfermedad hubiese sido mucho más instructiva! Únicamente una vez he encóntrado esta representación de una enfermedad que había sido objeto de un milagro terapéutico. Visitaba un santuario venerado del sur de Francia, en la Camargue, la iglesia des Saintes-Maries. Entre los exvotos distinguí el molde en yeso del miembro inferior de una niña de unos doce años patizamba. Este molde reproducía exactamente la contractura histérica del miembro inferior. La curación se efectuó rápidamente y al lado del molde se encontraba la fotografía de la niña, tiesa sobre su pierna, ya sin la contractura. Aparte de este ejemplo, el arte del modelador de piezas para los santuarios no nos enseña nada preciso sobre las enfermedades que se curan bajo la influencia de la faith-healing.

Pero hay otros documentos figurativos que van a sernos de gran utilidad. Los trabajos de Paul Girard, antiguo alumno de la escuela de Atenas, nos han enseñado que 
las murallas del Asclepión estaban cubiertas de pinturas votivas que representaban, al menos en parte, curaciones milagrosas que habían tenido lugar en ese lugar santo. A diferencia de los exvotos de metal o de mármol, estas pinturas no han resistido la acción del tiempo pero las encontramos adornando santuarios más modernos o ilustrando obras como los anales. Así pues podemos razonar por analogía. En el libro que he publicado en colaboración con Paul Richer, Les démoniaques dans l'art', se encuentran numerosas reproducciones de esas obras de la Edad Media y del Renacimiento.

Estas reproducciones de curaciones milagrosas se parecen todas con las variaciones que el genio particular del artista les haya impreso: se trata casi siempre, si no siempre, de la curación de enfermos convulsionarios. La representación es idéntica en el evangeliario de la biblioteca de Rávena que data del siglo VI de nuestra era, sobre la puerta de bronce de san Zenón en Verona (siglo XI), o en los cuadros de Rubens o de Jordaens que adornan los santuarios religiosos o los museos particulares o públicos, que a menudo los han sacado de esos santuarios. La unanimidad de esos documentos es notable. San Nil, santo Doíningo, san Ignacio, san Martín, han ejercido con un parecido sorprendente su poder milagroso para acabar con convulsiones cuyo origen histérico es indudable.

¿Pero la faith-healing sólo influye sobre las convulsiones histéricas? No. Las demás manifestaciones de la neurosis, tan numerosas, también se ven afectadas y encontramos la prueba tanto en documentos figurativos como en documentos escritos.
En el siglo XIII, en la basílica de Saint-Denis, la tumba de san Luis se convirtió en un frecuentado lugar de peregrinaje; al tocarla se producían numerosos milagros. Littré nos los ha referido e interpretado en La philosophie positive ${ }^{8}$. Es obvio que se trataba de contracturas histéricas.

En una época más reciente, en el siglo XVIII, el documento figurativo se asocia al documento escrito y la obra de Carré de Montgeron, cuyas planchas grabadas del natural representan muchas curaciones milagrosas, es una mina preciosa de información. Encontramos ahí la historia ilustrada de la curación milagrosa de la señorita Fourcroy y de Marie-Anne Couronneau, enfermas de parálisis y de contracturas histéricas. Tomo estos dos casos al azar entre los numerosos casos que relata Carré de Montgeron: todos se parecen. A quienes me reprochan que siempre hablo de la histeria, y antes de dar más explicaciones, les responderé con estas palabras de Molière: "Digo lo mismo porque siempre es lo mismo"; lo constato, y nada más.

Pero, se me responderá, los médicos que hoy -como antaño en el Asclepiónse encargan de comprobar los milagros que se dan en los santuarios pretenden que la curación de las convulsiones, de las contracturas y de las parálisis de origen histérico, es de un orden demasiado natural como para justificar una intervención milagrosa. Ellos también conocen la influencia de la mente sobre el cuerpo, y la desaparición espontánea de las parálisis histéricas no es óbice para que se apele a una fuerza sobrenatural. Pero el agua de la piscina se dirige ahora a los tumores, a las llagas; cura repentinamente las úlceras más

\footnotetext{
${ }^{7}$ Delahaye et Lecrosnier, París, 1887.

${ }^{8}$ Littré. Un fragment de médicine rétrospective. La philosophie positive. 1866, t. V, p. 103.
} 
HISTORIA

rebeldes; ¿se dirá también ahora que nacieron bajo la influencia de la neurosis?

En lo referente a los hechos, la evolución de nuestros datos científicos me permite tener la misma opinión que los médicos de los santuarios: algunos tumores y algunas úlceras se someten a la faithhealing, que toma su fuente de las aguas de la piscina sagrada.

¿Se trata de hechos nuevos? Toda la vida la faith-healing ha curado tumores y úlceras, $y$ añado que al igual que hoy en día esta curación se ha dado en unas condiciones perfectamente determinadas que casi siempre podemos analizar de forma exacta. Si se me permite citaré un ejemplo.

Carré de Montgeron nos ha referido detalladamente la curación milagrosa de la señorita Coirin, dándonos su descripción y su representación figurativa ${ }^{9}$.

En septiembre de 1716 la señorita Coirin, que entonces contaba con treinta y un años, se cayó del caballo dos veces seguidas: la segunda vez fue "del lado izquierdo del estómago cayendo a plomo sobre un montón de piedras, lo que le causa un dolor tan vivo que se desmaya".

Al cabo de cuarenta días tiene vómitos de sangre que se repiten frecuentemente acompañados de una "debilidad".

"En uno de esos estados de debilidad que le sobrevino tres meses después de su caída, al ponerse la ropa interior se dio cuenta de que tenía el seno izquierdo muy duro, inflado y amoratado. El cirujano, llamado Antoine Paysant, examinó su seno descubriendo que tenía una grueso ganglio que se extendía hacia atrás hasta la axila y una especie de gruesa cuerda de tres dedos de ancho que llegaba hasta el pezón. El cirujano le aplicó cataplasmas que le hicieron destilar una cantidad considerable de sangre por el pezón sin curarla ni aliviarla siquiera, su seno le seguía doliendo y estaba cada vez más duro.

...Se dio cuenta de que tenía un cáncer en el seno izquierdo, la mama de ese lado se había hecho tan grande como la cabeza, muy dura e inflamada".

Esto sucedió en 1716. "Sin embargo, el carácter tajante y corrosivo del cáncer hacía funestos progresos que por fin se manifestaron de la manera más horrible a finales del año 1719”.

Un testigo ocular, Anne Giroux, nos dice "que se le hizo una pequeña herida gangrenosa por debajo del seno izquierdo; que esta herida creció cada vez más llegando hasta alrededor del pezón y que en pocos días lo rodeó de forma que el pezón de ese seno se desprendió. Añade que vio el pezón desprendido de la mama, que lo guardó tres días en una servilleta para enseñárselo a los cirujanos que cuidaban de la mencionada señorita, y que ésta tenía o que había en lugar del pezón un agujero un poco más ancho que una moneda de doce soles que parecía bastante profundo y del que salía sin cesar un agua que olía a carroña".

En 1720 dos cirujanos propusieron la amputación del seno pero la madre de la señorita Coirin no consintió la operación al no ser ésta más que un paliativo pues el cáncer se tenía por incurable. "Ya que no era seguro

${ }^{9}$ Carré de Montgeron. La vérité des miracles opérés par M. de Pâris et autres appelans. Colonia, 1747, t. I. Séptima demostración. 
que su hija curase mediante esta operación era mejor ahorrársela y si al final iba a morirse era mejor que no sufriese".

Añadamos que desde 1718 la enferma quedó paralizada de golpe, en una noche, de todo el lado derecho.

"Fue presa de un entumecimiento del brazo izquierdo que por la noche degeneró en una parálisis que la privó del uso de todo el lado izquierdo; desde entonces no le ha sido posible mover el brazo ni la mano izquierda, que siempre están fríos como el hielo, ni tampoco cambiarlos de sitio más que cogiéndolos con su brazo derecho, o empujando su pierna izquierda con la derecha, este estado de cosas se mantuvo hasta la noche del 11 al 12 de junio de 1731. Incluso su muslo y su pierna se encogieron de forma que tenía un hueco por debajo de la cadera lo bastante profundo como para meter el puño, y como los nervios de la pierna se habían encogido parecía que era más corta que la otra... Su pierna izquierda estaba encogida hacia atrás y como retorcida, y estaba blanca, reseca, fría como el hielo incluso en la canícula".

El 9 de agosto de 1731 se dirigió a una virtuosa mujer de Nanterre y le encargó una novena en la tumba del beato François de Pâris, le pidió que rozara esta tumba con una camisa y le llevara un poco de la tierra cercana al sepulcro. El día siguiente, 10 de agosto, la piadosa mujer fue a Saint-Médard...

La noche del día 11 de agosto, apenas la moribunda se puso la camisa que había tocado la preciosa tumba, experi- mentó al instante la fuerza bienhechora que en ella estaba agotada. Forzada por su parálisis a estar tendida de espaldas se incorporó sola de la cama".

El día siguiente, 12 de agosto, se apresuró a aplicarse la preciosa tierra sobre su "cáncer" y "enseguida notó admirada que el profundo agujero de su seno de donde desde hacía doce años salía sin cesar un pus corrompido e infectado se secaba en el acto y empezaba a cerrarse y a curarse".

La noche siguiente, nuevo prodigio. "Los miembros paralíticos que desde hacía tantos años parecían con su frío glaciar los miembros de un cuerpo muerto, sus horribles marcas y su horroroso encogimiento, se reaniman de golpe; su brazo retoma la vida, el calor y el movimiento; su pierna encogida y seca se despliega y estira; el hueco de su cadera se rellena y desaparece; desde ese primer día intenta servirse de sus miembros revividos pero su delgadez muestra aún el sello de la muerte; se levanta sola, se sostiene sobre la punta del pie de esa pierna que desde hacía tanto tiempo era mucho más corta que la otra; utiliza con soltura su brazo izquierdo, se viste y se peina con sus manos".

El milagro se ha consumado: de todas formas hay que añadir que la llaga del seno no cicatrizó completamente hasta finales de mes; que sólo el veinticuatro de septiembre pudo salir a la calle y el treinta de septiembre montar en carruaje.

Confieso que hace sólo diez años la interpretación de todos los elementos de esta curiosa historia hubiese ofrecido mu- 
chas dificultades; no se hubiese dudado de la naturaleza histérica de los vómitos de sangre o de la parálisis, pero esta parálisis se acompañaba de atrofia. Tras haberse publicado ya más de veinte casos análogos al de la señorita Coirin, hoy está totalmente demostrado que la atrofia muscular acompaña muy a menudo a la parálisis o a la contractura histérica.

¿Pero, se dirá, el cáncer de mama, ese cáncer ulceroso, era también una manifestación histérica? Claro que sí, con tal de que el término "cáncer" no se tome aquí al pie de la letra y en su acepción histológica moderna. Las ulceraciones persistentes de la piel no son raras en la neurosis, prueba de ello son las llagas de san Francisco de Asís y los estigmas de Louise Lateau.

La señorita Coirin presentaba en el seno esos fenómenos de edema histérico mencionados por primera vez por el ilustre Sydenham, edema duro, edema azul o violáceo, como lo he llamado yo, y tras los trabajos del profesor Renaut ${ }^{10}$ de Lyon se sabe hoy que cuando el edema llega a cierto grado de intensidad puede entrañar gangrenas cutáneas cuyas escaras dejan a su vez ulceraciones análogas a la que destruyó el pezón en el caso citado" ${ }^{11}$.

Hace poco leía un informe muy interesante del Dr. Fowler ${ }^{12}$. Expone ocho casos en los que existían en el seno tumores aislados o múltiples a veces mayores que un huevo de gallina.

Varias enfermas consultaron a cirujanos célebres; la mayoría parece que consideraron la afección del seno de na- turaleza orgánica y propusieron la ablación del órgano. Ahora bien, el Dr. Fowler, más sagaz, sometió a sus pacientes, todas histéricas, a un tratamiento cuya parte más importante correspondió al elemento psíquico y los tumores que se habían creído destinados al bisturí pronto desaparecieron. $\mathrm{Si}$ fueron al santuario con tales diagnósticos de neoplasia, de cáncer quizás, ¿cómo poner en duda que se hubiesen curado de una enfermedad tenida por incurable? El Dr. Fowler conocía bien la influencia de la faith-healing en sus enfermas pues nos lo dice con todas sus letras al hablar de una de ellas, y probablemente pasaba lo mismo con las demás: Like all women of similar temperament, she had a fetish-like-faith in her regular medical attendant ${ }^{13}$.

Este caso y todos los demás muestran que la curación que algunos llaman sobrenatural acarreada por la influencia de la faith-healing obedece a leyes naturales, y éstas se hacen aún más evidentes al profundizar en el análisis de los hechos. Por ejemplo, en todos los casos lo repentino de la curación es mucho más aparente que real.

Tomemos por ejemplo la contractura histérica. Bajo la influencia de la faithhealing o de cualquier otra causa más o menos milagrosa, cesa la rigidez, los músculos vuelven a funcionar. En ese momento y en los días siguientes un examen atento muestra que en el miembro que tuvo la contractura persisten problemas de sensibilidad y exageración de los reflejos tendinosos, compañeros ambos de la contractura. Debido a las leyes fisiológicas esos fenómenos no desaparecen inmediatamente y mientras persisten puede temerse un retorno de la parálisis o de la

\footnotetext{
${ }^{10}$ Renaut. "Sur une forme de gangrène successive et disséminée de la peau, l'urticaire gangréneuse". La médicine modeme 9, 20 de febrero de 1890.

"La historia completa de estos problemas tróficos se encuentra en el Traité clinique et thérapeutique de l'hystérie, de mi antiguo jefe de clínica Gilles de la Tourette. Plon, París, t. I 1891, t. II en preparación.

12 "Neurotic Tumours of the Breast, read before the New York Neurological Society", 7 de enero de 1890. Medical Recond, 15 de febrero de 1890 , p. 179.

${ }^{13} \mathrm{~N}$. T. [Como todas las mujeres con un carácter parecido, tenía una fe fetichista en su médico de cabecera].
} 
contractura, tal como a menudo he mostrado en mi Clínica. No se puede ni soñar con encontrar tales fenómenos en los santuarios pero los he observado a menudo tanto en enfermos que se han curado en un lugar santo como en aquellos cuya curación se ha conseguido en la Salpêtrière: las diferencias no están en los hechos sino en su interpretación.

Abundando en ello, este determinismo es aún más evidente cuando la parálisis se acompaña de atrofia o cuando el edema produce la gangrena cutánea, fenómenos cuya evolución pueden apreciar hasta los observadores menos experimentados.

Tras estas apreciaciones, volvamos a la señorita Coirin. El edema, problema vasomotor, desapareció casi inmediatamente bajo la influencia psíquica determinada por la aplicación de la camisa que tocó la tumba del diácono de Pâris, el seno retomó su volumen normal. En este hecho no hay nada que pueda asombrarnos pues sabemos con qué rapidez pueden aparecer y desaparecer los problemas circulatorios. Al desaparecer el edema las condiciones locales de nutrición de los tejidos se modifican, la llaga del seno se cicatrizará en virtud de leyes fisiológicas tan conocidas como las que antes habían presidido la aparición de la gangrena. Pero la cicatrización completa requiere un tiempo, y en efecto no fue sino hasta después de quince días cuando la piel del órgano se alisó, indemne de toda ulceración y en vías de cicatrización.

El elemento contracturado o paralizado puede aparecer o desaparecer repen- tinamente. Es un hecho bien conocido que una violenta emoción nos clava al suelo sin que podamos movernos. Cuando el influjo motor cerebral se restablece estamos en condiciones de andar de nuevo. Pero si durante esta parálisis los músculos se atrofian, entonces el miembro no retoma su fuerza y su volumen hasta que los haces musculares se regeneran, y esta regeneración presidida también por leyes físicas requiere un tiempo. Tal es el caso de la señorita Coirin que no pudo servirse de su pierna atrofiada para montar en carruaje hasta veinte días después de su curación calificada de repentina.

También es el caso de Philippe Sergent que refiere Carré de Montgeron. El 10 de julio de 1730 , tercer día de su novena en la tumba del diácono de Pâris, se curó de una contractura con atrofia de los miembros del lado derecho. "Pero, dice explícitamente el narrador, su mano, su cadera y su pierna derechas no volvieron a fortalecerse en el momento sino que sólo retomaron el color de la carne", pues, como en el caso de la señorita Coirin, se trataba de un edema azul histérico. La atrofia no pudo escapar a las leyes fisiológicas de la regeneración muscular.

En este sentido, puedo invocar también mis experiencias particulares. He visto regresar de santuarios de moda a enfermos enviados con mi consentimiento al no haber podido yo mismo inspirarles la faithhealing. He examinado sus miembros enfermos algunos días antes de parálisis o de contracturas y he asistido a la desaparición gradual de los estigmas sensitivos locales que persisten casi siempre algún tiempo tras la curación del elemento paralizado o contracturado ${ }^{14}$. 
HISTORIA

\section{V}

En resumen, creo que la faithhealing necesita unos sujetos determinados y unas enfermedades específicas, que se someten a la influencia que la mente posee sobre el cuerpo. Los histéricos presentan un estado mental eminentemente favorable al desarrollo de la faith-healing pues son sugestionables en sumo grado, bien se ejerza la sugestión a través de elementos exteriores o bien extraigan de sí mismos los elementos tan poderosos de la autosugestión. En esos individuos, hombres o mujeres, la influencia de la mente sobre el cuerpo es lo bastante eficaz como para producir la curación de enfermedades que la ignorancia de su verdadera naturaleza, como pasaba hace bien poco, hacía que se considerasen incurables. En- fermedades como los problemas tróficos de origen histérico que hoy se empiezan a comprender: atrofia muscular, edemas, tumores con ulceraciones. Cuando oigamos hablar de una curación repentina de un cáncer ulceroso de seno en un santuario, recordemos el caso de la señorita Coirin y las modernas observaciones del Dr. Fowler.

¿Quiere esto decir que ya lo conocemos todo sobre ese dominio de lo sobrenatural sometido totalmente a la faithhealing y que ve replegarse sus fronteras cada día bajo la influencia de los descubrimientos científicos? No. Hay que ser paciente y seguir investigando. Soy el primero en reconocer que hoy:

There are more things in heaven and earth Than are dreamt in of our philosophy ${ }^{15}$.

${ }^{15} \mathrm{~N}$. T. [Hay más cosas en el cielo y la tierra de las que puede imaginar nuestra filosofía], en Hamlet de William Shakespeare.

*Prof. Titular interino de H.a de la Psicología

Universidad de Jaen

Paraje de las Lagunillas, s/n

23071 JAEN 